\title{
An Activity-Based Probe for Cathepsin K Imaging with Excellent Potency and Selectivity
}

Carina Lemke, ${ }^{\S}$ Jakub Benýšek, ${ }^{\ddagger \neq \chi}$ Dominik Brajtenbach, ${ }^{\S}$ Christian Breuer, ${ }^{\S, \Psi}$ Adéla Jílková, ${ }^{\ddagger}$ Martin Horn, ${ }^{\ddagger}$ Michal Buša, ${ }^{\ddagger \neq}$ Lenka Ulrychová, ${ }^{\star}$ Annika Illies, ${ }^{\S}$ Katharina F. Kubatzky, Ulrike Bartz, ${ }^{\Psi}$ Michael Mareš ${ }^{*}, *$ and Michael Gütschow ${ }^{*}, \S$

$\S$ Pharmaceutical Institute, Pharmaceutical \& Medicinal Chemistry, University of Bonn, An der Immenburg 4, 53121 Bonn, Germany.

$\$$ Institute of Organic Chemistry and Biochemistry of the Czech Academy of Sciences, Flemingovo n. 2, 16610 Prague, Czech Republic.

$\chi$ First Faculty of Medicine, Charles University, Kateřinská 32, 12108 Prague, Czech Republic.

${ }^{\Psi}$ Department of Natural Sciences, University of Applied Sciences Bonn-Rhein-Sieg, vonLiebig-Str. 20, 53359 Rheinbach, Germany.

${ }^{¥}$ Department of Biochemistry, Faculty of Science, Charles University, Hlavova 8, 12800 Prague, Czech Republic.

- Department of Infectious Diseases, Medical Microbiology and Hygiene, Heidelberg University Hospital, Im Neuenheimer Feld 324, Heidelberg, Germany.

Corresponding Authors

* Email: mares@uochb.cas.cz (M.M.)

* Email: guetschow@uni-bonn.de (M.G.) 


\section{Table of Contents}

Supporting Figures and Tables.......................................................................... S3

Figure S1. Kinetic evaluation of precursor 22 with cathepsin K.............................. S3

Table S1. X-ray data collection and refinement statistics......................................... S4

Table S2. List of contacts formed between cathepsin K and ligands.......................... S5

Figure S2. Selectivity of ABP 25. Experiments with related cysteine cathepsins and

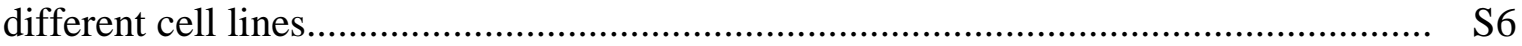

Figure S3. Fluorescence detection of human cathepsin K with ABP 24.................... S7

Figure S4. Imaging of human cathepsin K with ABP 24 in the presence of cell lysate.

HPLC Purity Traces for Compounds with in vitro Data................................................ S9

NMR Spectra of Compounds with in vitro Data............................................................... S13

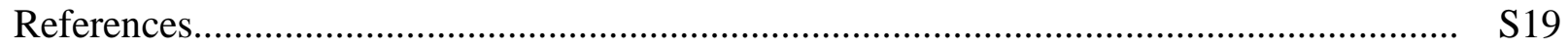




\section{Supporting Figures and Tables}
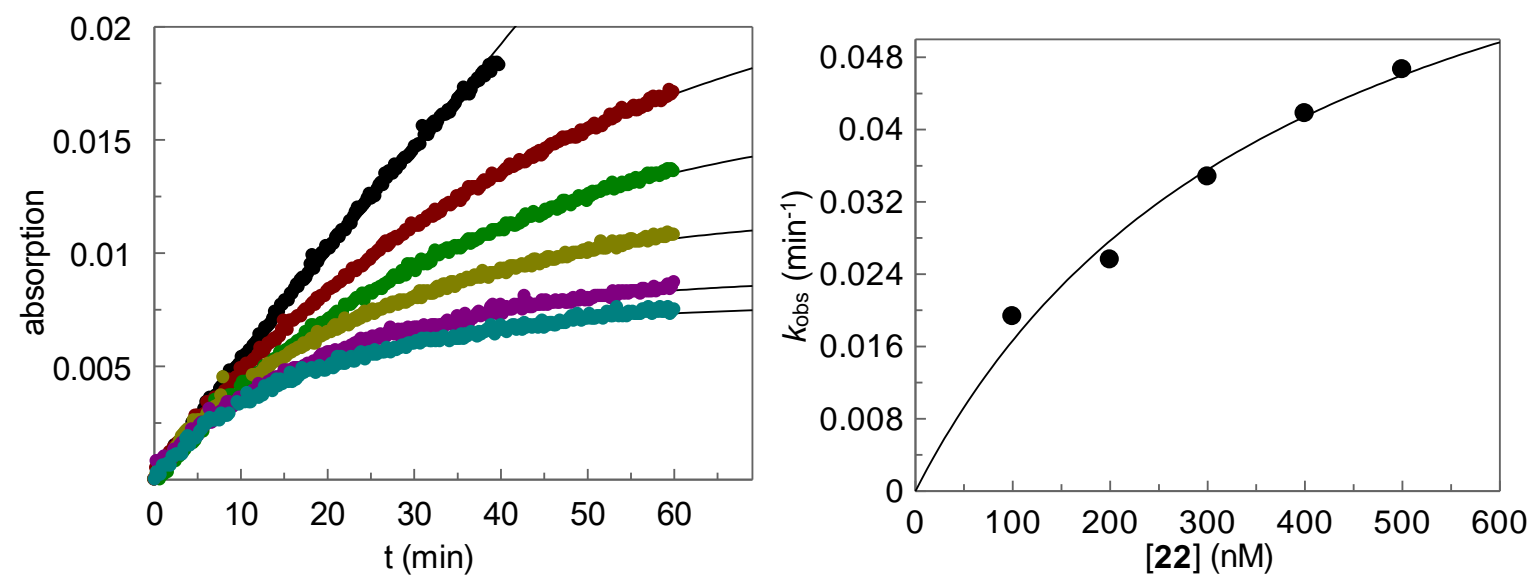

Figure S1. Kinetic evaluation of precursor 22 with cathepsin K. Left: Product formation is measured as absorption versus time. From top to bottom: 0 nM, 100 nM, 200 nM, 300 nM, $400 \mathrm{nM}, 500 \mathrm{nM}$. From these progress curves, first-order rate constants $k_{\mathrm{obs}}$ were determined following the equation $[\mathrm{P}]=v_{\mathrm{i}} \times\left(1-\exp \left(-k_{\mathrm{obs}} \times \mathrm{t}\right)\right) / k_{\mathrm{obs}}+\mathrm{d}$, where $[\mathrm{P}]$ is the product concentration, $v_{\mathrm{i}}$ is the initial product formation rate, $\mathrm{t}$ is the time, and $\mathrm{d}$ is the offset. Right: The mean of the $k_{\mathrm{obs}}$ values was plotted versus the inhibitor concentrations [I]. Non-linear regression was performed to obtain second-order rate constants $k_{\text {inac }} / K_{\mathrm{i}}$ using the equation $k_{\text {obs }}=k_{\text {inac }} \times[\mathrm{I}] /\left(K_{\mathrm{i}}+[\mathrm{I}]\right)$, with $k_{\text {inac }}$ as the first-order rate constant of inactivation and $K_{\mathrm{i}}$ as the inhibitory constant. $K_{\mathrm{i}}$ values were additionally corrected by means of the Cheng-Prusoff equation. 
Table S1. X-ray data collection and refinement statistics

\begin{tabular}{|c|c|c|}
\hline Cathepsin K-ligand complex & Cathepsin K-21 & Cathepsin K-25 \\
\hline \multicolumn{3}{|c|}{ Data collection statistics $^{a}$} \\
\hline Wavelength $(\AA)$ & 1.541 & 1.541 \\
\hline Space group & $P 22_{1} 2_{1}$ & $P 22_{1} 2_{1}$ \\
\hline Temperature (K) & 100 & 100 \\
\hline$a, b, c(\AA)$ & $32.37,71.82,80.78$ & $32.05,71.68,80.86$ \\
\hline$\alpha, \beta, \gamma(\mathrm{deg})$ & $90,90,90$ & $90,90,90$ \\
\hline \multirow[t]{2}{*}{ Resolution $(\AA)$} & $35.20-1.80$ & $35.84-1.72$ \\
\hline & $(1.865-1.80)$ & $(1.782-1.72)$ \\
\hline Number of total reflections & $106,253(6,827)$ & $65,175(968)$ \\
\hline Number of unique reflections & $18,053(1,705)$ & $17,404(552)$ \\
\hline$R_{\text {merge }}^{b}$ & $0.1468(1.211)$ & $0.0564(0.3496)$ \\
\hline Average $I / \sigma(I)$ & $9.60(1.06)$ & $15.85(2.08)$ \\
\hline Completeness (\%) & $99.57(96.99)$ & $85.38(27.25)$ \\
\hline Multiplicity & $5.9(4.0)$ & $3.7(1.8)$ \\
\hline $\mathrm{CC}_{1 / 2}^{c}(\%)$ & $99.6(46.0)$ & $99.8(81.5)$ \\
\hline Wilson B $\left(\AA^{2}\right)$ & 20.13 & 16.20 \\
\hline \multicolumn{3}{|c|}{ Refinement statistics $^{a}$} \\
\hline Resolution range $(\AA)$ & $\begin{array}{l}35.20-1.80 \\
(1.865-1.80)\end{array}$ & $\begin{array}{l}35.84-1.72 \\
(1.782-1.72)\end{array}$ \\
\hline Number of reflections in working set & $18,050(1,705)$ & $17,510(552)$ \\
\hline Number of reflections in test set & $910(80)$ & $895(39)$ \\
\hline$R$ value $^{d}(\%)$ & $17.46(31.25)$ & $16.08(26.04)$ \\
\hline$R_{\text {free }}$ value $^{e}(\%)$ & $20.94(31.74)$ & $19.08(31.22)$ \\
\hline $\begin{array}{l}\text { Number of atoms in } \mathrm{AU}^{f} \\
\text { protein/inhibitor/solvent }\end{array}$ & $1,674 / 36 / 172$ & $1,692 / 32 / 184$ \\
\hline $\begin{array}{l}\text { Average } \mathrm{ADP}^{g} \text { for } \\
\text { protein/inhibitor/solvent }\left(\AA^{2}\right)\end{array}$ & $23.92 / 43.32 / 30.69$ & $17.93 / 38.16 / 27.80$ \\
\hline RMSD bond length $(\AA)$ & 0.015 & 0.015 \\
\hline RMSD bond angle (deg) & 1.87 & 1.80 \\
\hline \multicolumn{3}{|l|}{ Ramachandran plot statistics ${ }^{h}$} \\
\hline favored regions $(\%)$ & 96.3 & 96.7 \\
\hline allowed regions (\%) & 3.7 & 3.3 \\
\hline PDB code & 7NXL & $7 \mathrm{NXM}$ \\
\hline
\end{tabular}

${ }^{a}$ Numbers in parentheses refer to the highest-resolution shell. ${ }^{b} R_{\text {merge }}=100 \sum_{h k l} \sum_{i}\left|\mathrm{I}_{i}(h k l)-\langle\mathrm{I}(h k l)\rangle\right| \sum_{h k l} \sum_{i} \mathrm{I}_{i}(h k l)$, where $\mathrm{I}_{i}(h k l)$ is an individual intensity of the $i^{\text {th }}$ observation of reflection $h k l$ and $\langle\mathrm{I}(h k l)\rangle$ is the average intensity of reflection $h k l$ with summation over all data. ${ }^{c} \mathrm{CC}_{1 / 2}$ is the percentage of correlation between intensities from random half-datasets. ${ }^{1}{ }^{d} R$ value $=\| F_{o}|-| F_{c}||\left|F_{o}\right|$, where $F_{o}$ and $F_{c}$ are the observed and calculated structure factors, respectively. ${ }^{e} R_{\text {free }}$ is equivalent to $R$ value but is calculated for up to $5 \%$ of the reflections chosen at random and omitted from the refinement process. ${ }^{2}{ }^{f} \mathrm{AU}$, asymmetric unit. ${ }^{g} \mathrm{ADP}$, atomic displacement parameter, formally B-factor. ${ }^{h}$ As determined by Molprobity. ${ }^{3}$ 
Table S2. List of contacts formed between cathepsin K and ligands. ${ }^{a}$

\begin{tabular}{|c|c|c|c|c|c|c|}
\hline \multirow{2}{*}{ Position } & \multicolumn{3}{|c|}{ Precursor 21} & \multicolumn{3}{|l|}{ Probe $\mathbf{2 5}$} \\
\hline & Residue & $\mathrm{C}^{b}$ & $\mathrm{Hb}^{b}$ & Residue & $\mathrm{C}$ & $\mathrm{Hb}$ \\
\hline \multirow{12}{*}{ P1' } & Gln19 & 6 & \multirow[t]{12}{*}{1} & Gln19 & 5 & \multirow[t]{12}{*}{1} \\
\hline & Gly20 & 1 & & Gly20 & 1 & \\
\hline & Gln21 & 1 & & $\mathrm{G} \ln 21$ & 2 & \\
\hline & Cys22 & 8 & & Cys22 & 10 & \\
\hline & Gly23 & 4 & & Gly23 & 7 & \\
\hline & Cys25 & 4 & & Cys25 & 3 & \\
\hline & Ala137 & 4 & & Ala137 & 5 & \\
\hline & Ser138 & 4 & & Ser138 & 3 & \\
\hline & Gln143 & 2 & & Gln143 & 2 & \\
\hline & Asn161 & 3 & & Asn161 & 6 & \\
\hline & His162 & 8 & & His162 & 4 & \\
\hline & Trp184 & 4 & & Trp184 & 3 & \\
\hline \multirow{5}{*}{ P1 } & Gln19 & 1 & \multirow{5}{*}{1} & Gln19 & 1 & \multirow{5}{*}{1} \\
\hline & Gly23 & 6 & & Gly23 & 6 & \\
\hline & Cys25 & 6 & & Cys25 & 7 & \\
\hline & Asn161 & 4 & & Asn161 & 4 & \\
\hline & His162 & 1 & & His162 & 1 & \\
\hline \multirow{13}{*}{$\mathrm{P} 2$} & Gly23 & 1 & \multirow{13}{*}{2} & Gly23 & 1 & \multirow{13}{*}{2} \\
\hline & Cys 25 & 2 & & Cys25 & 3 & \\
\hline & Trp26 & 4 & & Trp26 & 4 & \\
\hline & Gly65 & 3 & & Gly65 & 3 & \\
\hline & Gly66 & 12 & & Gly66 & 13 & \\
\hline & Tyr67 & 1 & & & & \\
\hline & Met68 & 2 & & Met68 & 2 & \\
\hline & Ala134 & 2 & & Ala134 & 2 & \\
\hline & Leu160 & 3 & & Leu160 & 3 & \\
\hline & Asn161 & 5 & & Asn161 & 4 & \\
\hline & His162 & 1 & & His162 & 1 & \\
\hline & Ala163 & 1 & & Ala163 & 1 & \\
\hline & Leu209 & 1 & & Leu209 & 1 & \\
\hline \multirow{5}{*}{ P3 } & Asp61 & 2 & \multirow{5}{*}{1} & & & \\
\hline & Gly64 & 2 & & & & \\
\hline & Gly65 & 5 & & & & \\
\hline & Gly66 & 7 & & Gly66 & 4 & \\
\hline & Tyr67 & 2 & & Tyr67 & 3 & \\
\hline
\end{tabular}

${ }^{a}$ Analysis of protein-inhibitor contacts between the cathepsin $\mathrm{K}$ active site and precursor $\mathbf{2 1}$ or probe $\mathbf{2 5}$ was performed using the program CONTACT. ${ }^{4}$ The fragmentation of ligands into segments (in red and black) corresponding to the $\mathrm{P} 3$ to $\mathrm{P} 1$ ' positions is depicted in the scheme; $\mathrm{R}$ is a tert-butyloxy group for $\mathbf{2 1}$ and an apparent methyl group (derived from the fluorescent tag) for $\mathbf{2 5}$. The distance cutoffs were set to $4.1 \AA$ for all contacts and $3.2 \AA$ for hydrogen bonds. The cathepsin $\mathrm{K}$ residues interacting with the individual ligand positions are specified. ${ }^{b}$ For each cathepsin $\mathrm{K}$ residue, total number of contacts (C) is listed, including hydrogen bonds (Hb). Residues forming hydrogen bonds are listed in bold. 

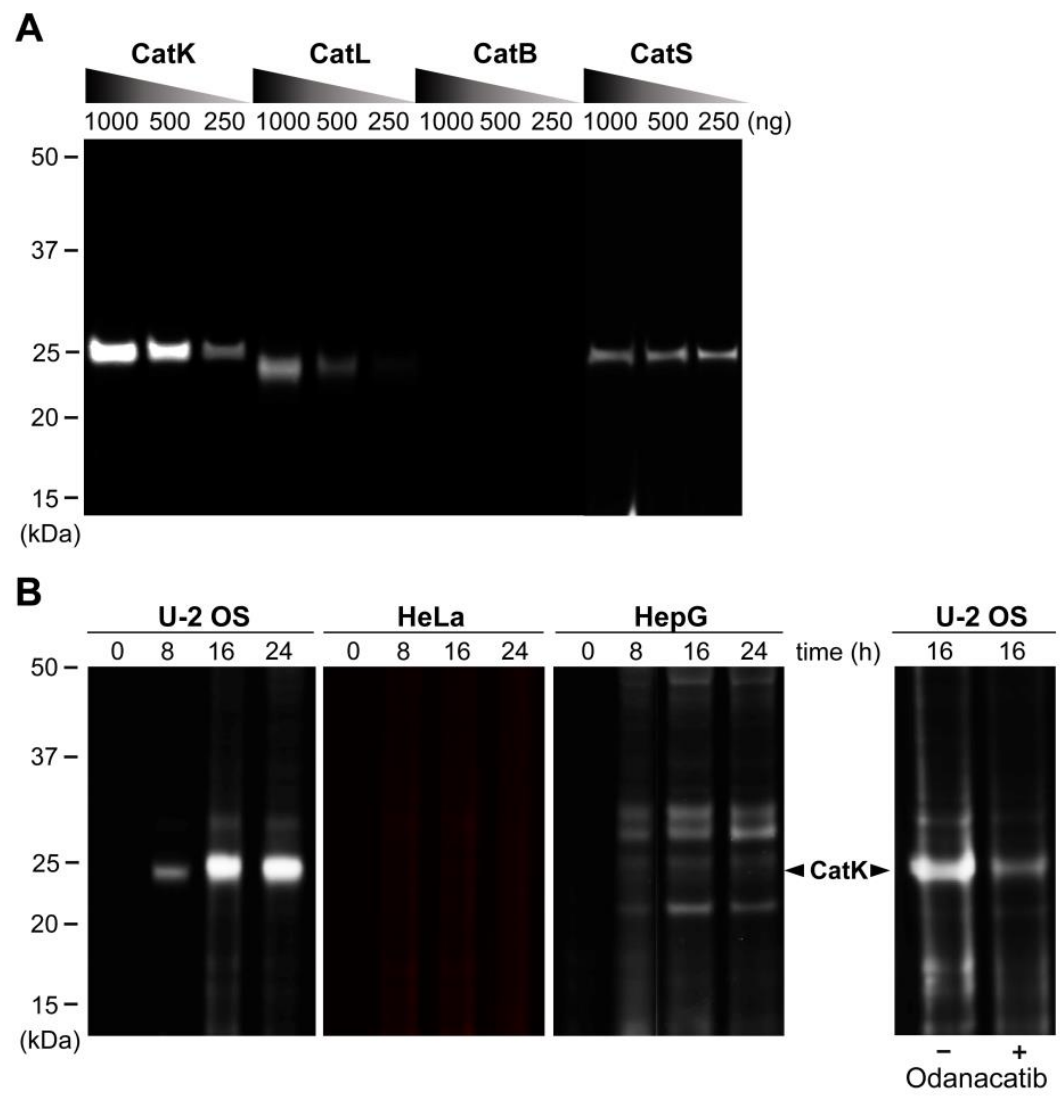

Figure S2. Selectivity of ABP 25. Experiments with related cysteine cathepsins and different cell lines. (A) Indicated amounts of recombinant human cathepsin K (CatK), purified human liver cathepsins L (CatL, Sigma) and B (CatB, Calbiochem) as well as recombinant human cathepsin S (CatS, Enzo Life Sciences) were incubated with ABP $25(5 \mu \mathrm{M})$ at $25{ }^{\circ} \mathrm{C}$ for $1 \mathrm{~h}$. The incubations were resolved by SDS-PAGE and visualized using a fluorescence scanner. (B) Imaging of CatK with ABP 25 in human osteosarcoma cells (U-2 OS), human epithelial cancer cells (HeLa), and human liver cancer cells (HepG). 50,000 cells each were seeded into a well of a 12-well plate and allowed to attach. The cells were incubated at $37{ }^{\circ} \mathrm{C}$ in $5 \% \mathrm{CO}_{2}$ with $25(1 \mu \mathrm{M})$ for the indicated time. After cell lysis with $100 \mu \mathrm{L}$ of SDS-PAGE loading buffer and heating at $100{ }^{\circ} \mathrm{C}$ for $10 \mathrm{~min}$, the samples were resolved by SDS-PAGE and visualized using a fluorescence scanner. Additionally, U-2 OS cells were treated with the covalent-reversible cathepsin $\mathrm{K}$-selective inhibitor odanacatib $(10 \mu \mathrm{M}, 1 \mathrm{~h})$ prior to treatment with ABP $25(1 \mu \mathrm{M})$. 


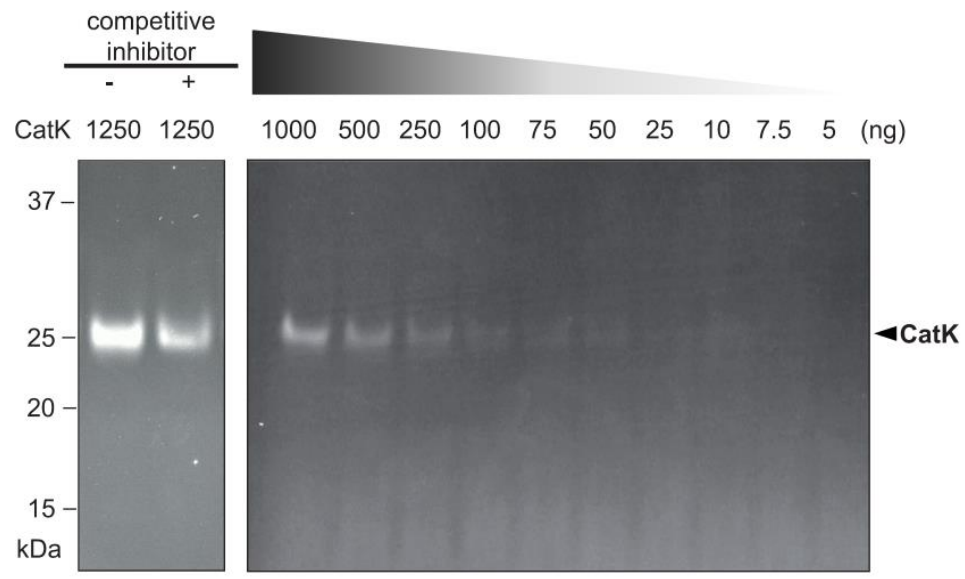

Figure S3. Imaging of human cathepsin K with ABP 24. Left: Purified recombinant cathepsin $\mathrm{K}(\mathrm{CatK}, 1.25 \mu \mathrm{g})$ was incubated with $24(5 \mu \mathrm{M})$. In the control experiment, the enzyme was pretreated with a mixture of the competitive inhibitors E-64/K11777 (both $10 \mu \mathrm{M}$ ) prior to incubation with $24(5 \mu \mathrm{M})$. Right: Cathepsin K (CatK, 1000-5 ng) was labeled with 24 (5 $\mu \mathrm{M})$. Incubations were performed for $1 \mathrm{~h}$ at $25^{\circ} \mathrm{C}$ and at $\mathrm{pH}$ 5.5. The reactions were resolved by SDS-PAGE and visualized with a Typhoon RGB imager using excitation at $488 \mathrm{~nm}$ and emission at $515 \mathrm{~nm}$. 


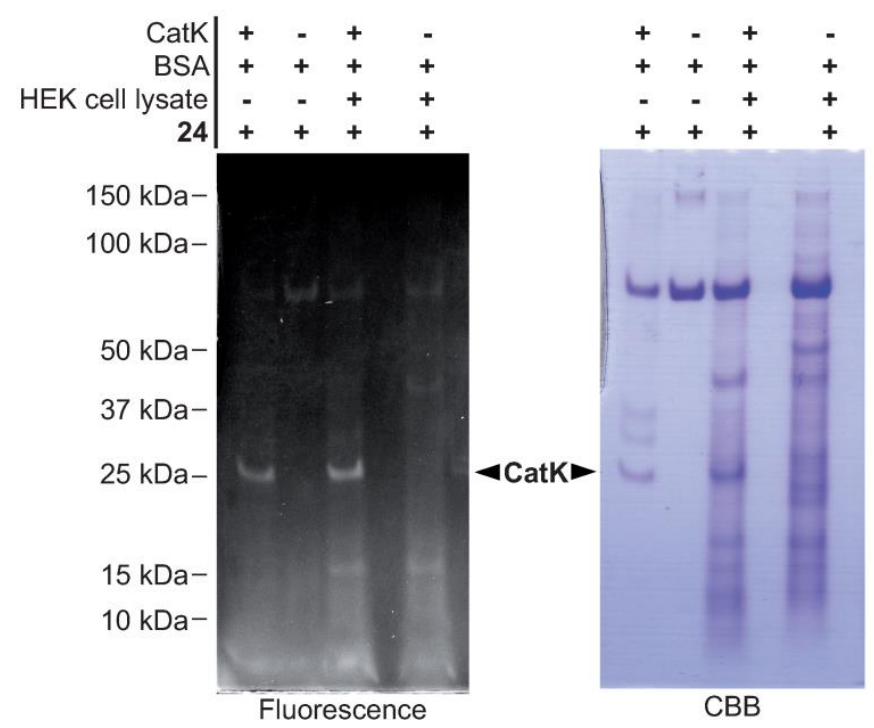

Figure S4. Imaging of human cathepsin K with ABP 24 in the presence of cell lysate. Human recombinant cathepsin $\mathrm{K}$ (CatK, $300 \mathrm{ng})$ was treated with ABP $24(5 \mu \mathrm{M})$ in the presence of HEK cell lysate $\left(30 \mu \mathrm{g}\right.$ ) and BSA (500 ng) for $1 \mathrm{~h}$ at $25{ }^{\circ} \mathrm{C}$ and $\mathrm{pH} 5.5$. In control experiments, cathepsin K (300 ng) and BSA (500 ng), or BSA (500 ng) alone, or HEK cell lysate $(30 \mu \mathrm{g})$ and BSA (500 ng) were treated with ABP $24(5 \mu \mathrm{M})$, separately. The reactions were resolved by SDS-PAGE and visualized with a Typhoon RGB imager using excitation at $488 \mathrm{~nm}$ and emission at $515 \mathrm{~nm}$ (Fluorescence, left) and subsequently stained with Coomassie Brilliant Blue (CBB, right). 


\section{HPLC Purity Traces and MS Signals for Compounds with in vitro Data}

HPLC traces were analyzed with HPLC/DAD/MS. The purity was determined based on area under the curve (AUC) values for absorption at 200-400 nm (21), 200-600 nm (22), 220-500 $(\mathbf{2 3}, \mathbf{2 4}), 220-700 \mathrm{~nm}(\mathbf{2 5}, \mathbf{2 6})$. Wavelengths ranges were selected with respect to compounds' spectroscopic properties. The sum of all AUCs except for that of the injection peak was set at $100 \%$.

HPLC-DAD trace of $\mathbf{2 1} t_{\mathrm{R}}=12.19 \min$, purity $=96.24 \%$

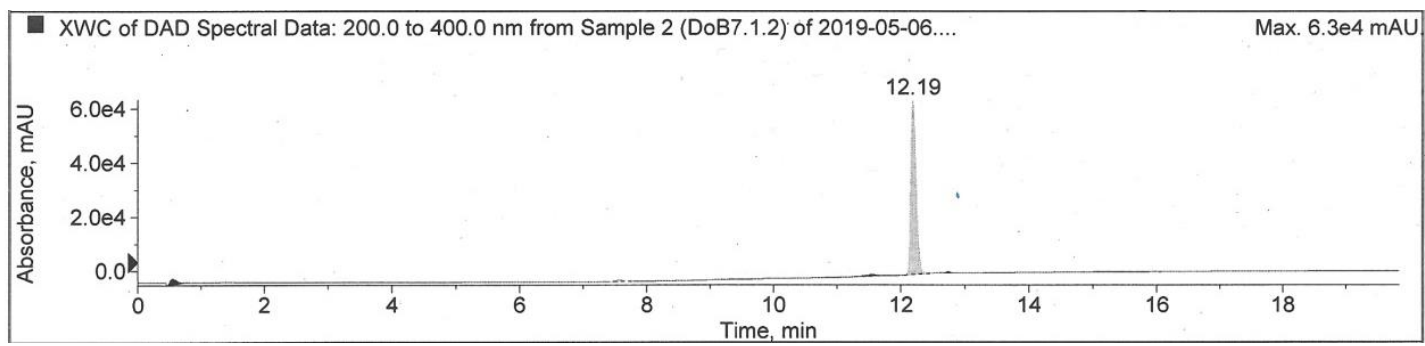

MS signal of 21

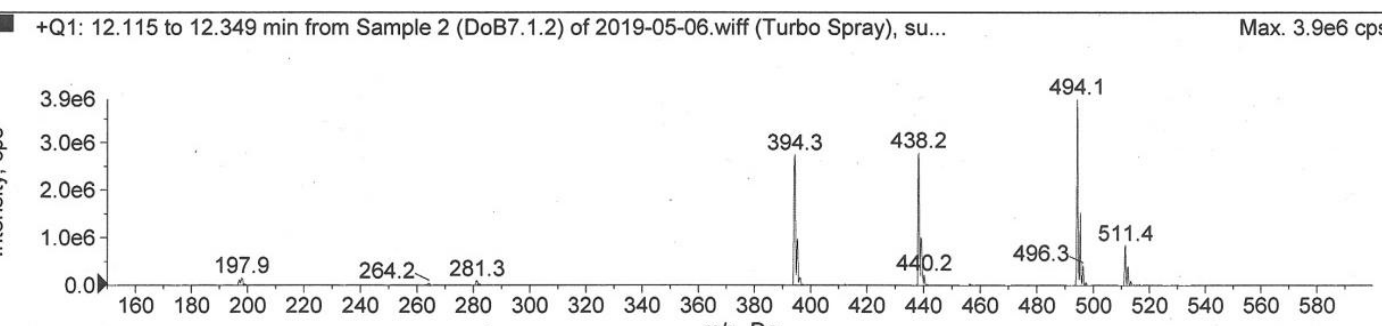


HPLC-DAD trace of $22 t_{\mathrm{R}}=8.80 \mathrm{~min}$, purity $=99.75 \%$

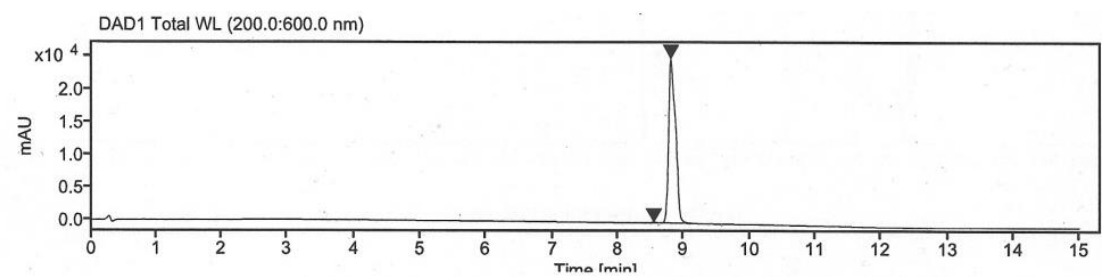

MS signal of 22

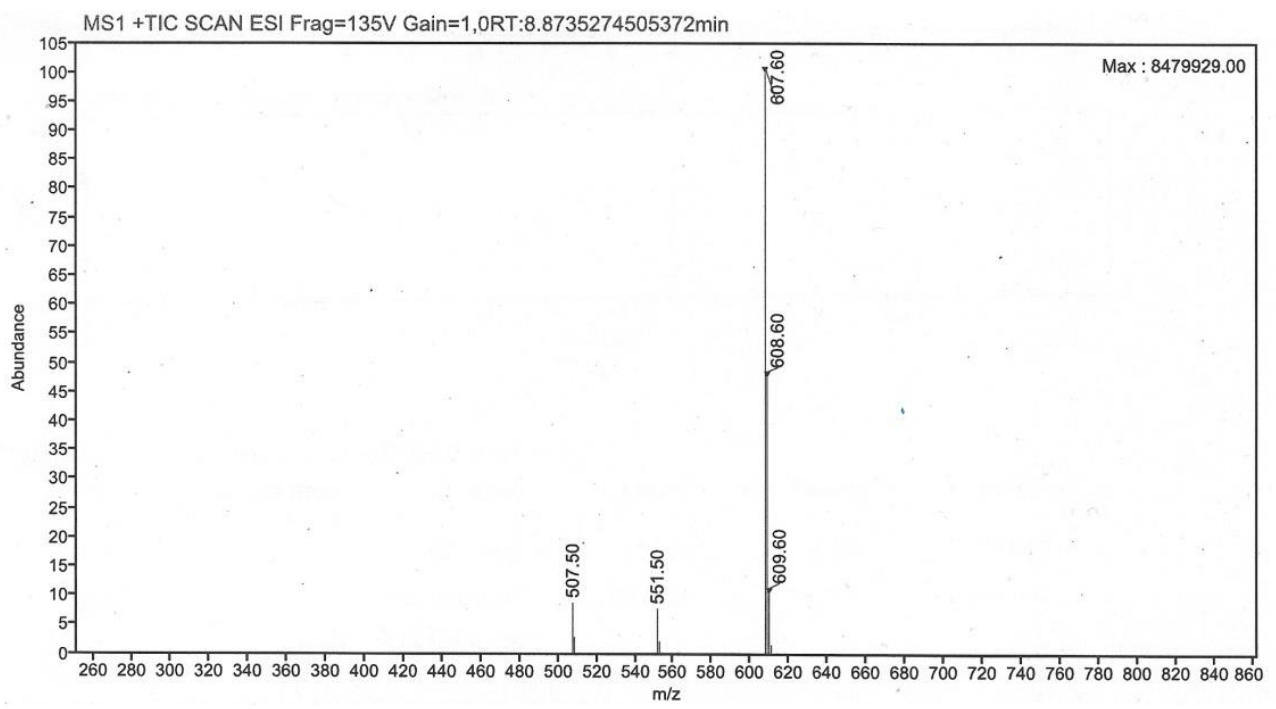

HPLC/DAD trace of $\mathbf{2 3} t_{\mathrm{R}}=12.63 \mathrm{~min}$, purity $=96.17 \%$

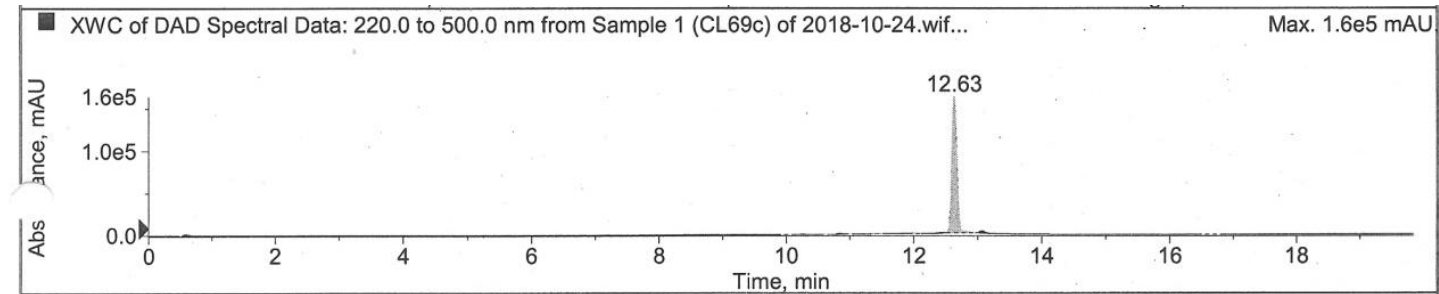

\section{MS signal of 23}

+Q1: 12.584 to 12.829 min from Sample 1 (CL69c) of 2018-10-24.wiff (Turbo Spray), subtr...

Max. $4.2 \mathrm{e} 5 \mathrm{cps}$

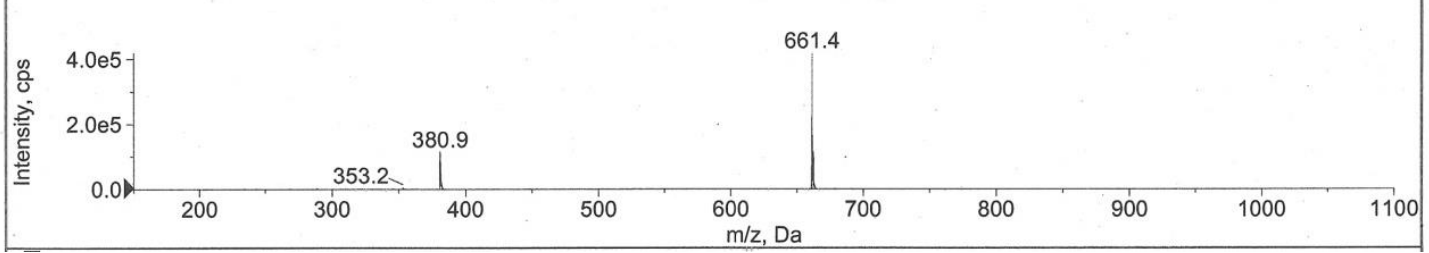


HPLC/DAD trace of $\mathbf{2 4} t_{\mathrm{R}}=13.07 \mathrm{~min}$, purity $=95.39 \%$

XWC of DAD Spectral Data: 220.0 to $500.0 \mathrm{~nm}$ from Sample 1 (СB225) of 2018-04-05.wif...

Max. 1.1e5 mAU

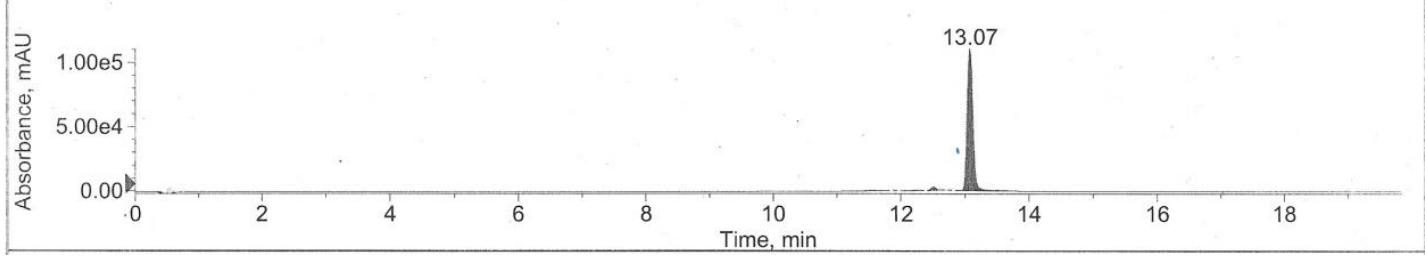

MS signal of $\mathbf{2 4}$

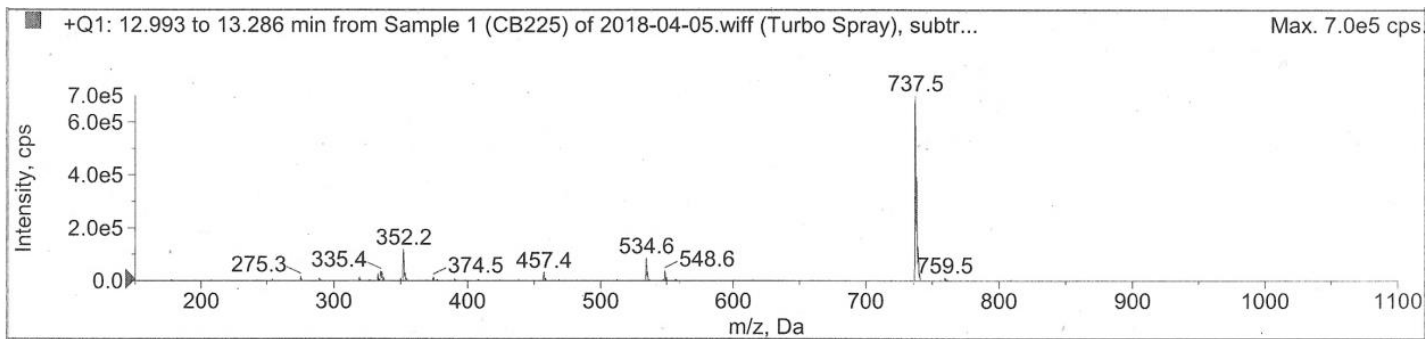

HPLC/DAD trace of $\mathbf{2 5} t_{\mathrm{R}}=12.09 \mathrm{~min}$, purity $=97.16 \%$

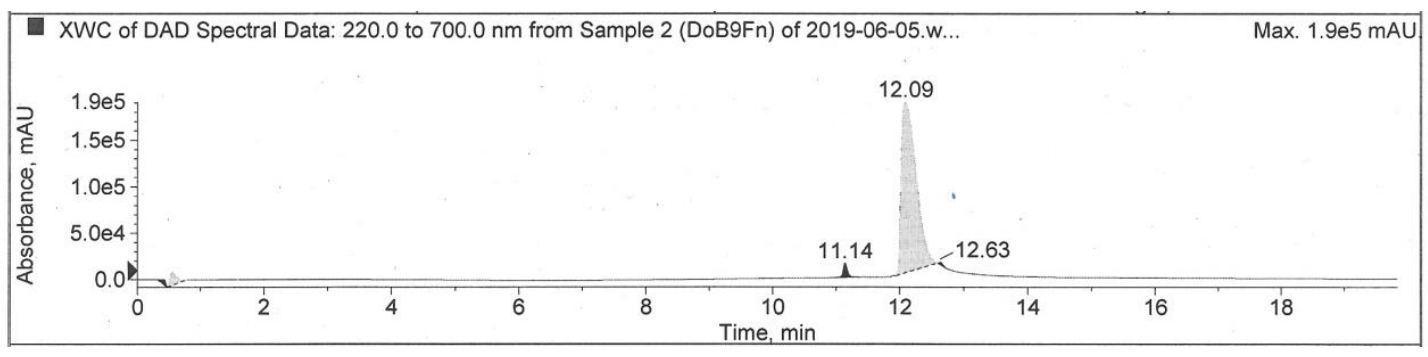

MS signal of 25

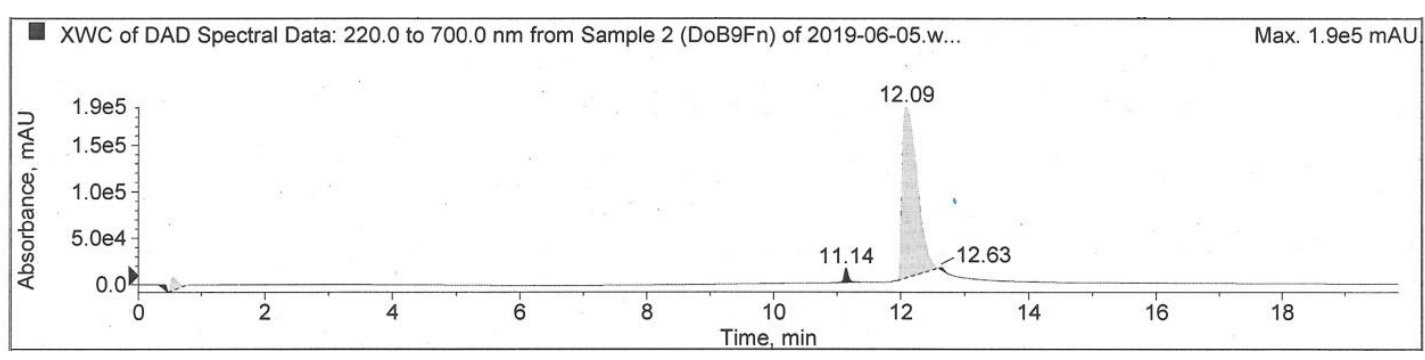


HPLC/DAD trace of $\mathbf{2 6} t_{\mathrm{R}}=12.56 \mathrm{~min}$, purity $=97.35 \%$

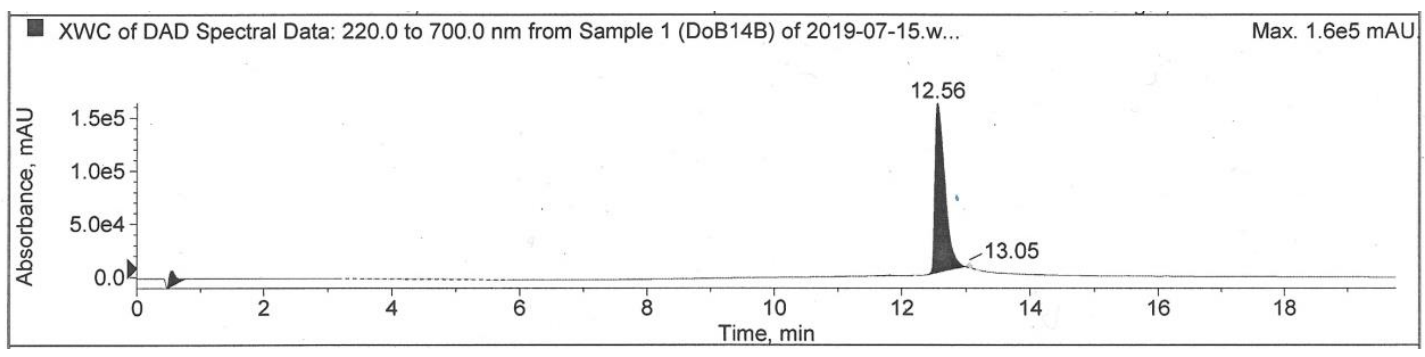

MS signal of $\mathbf{2 6}$

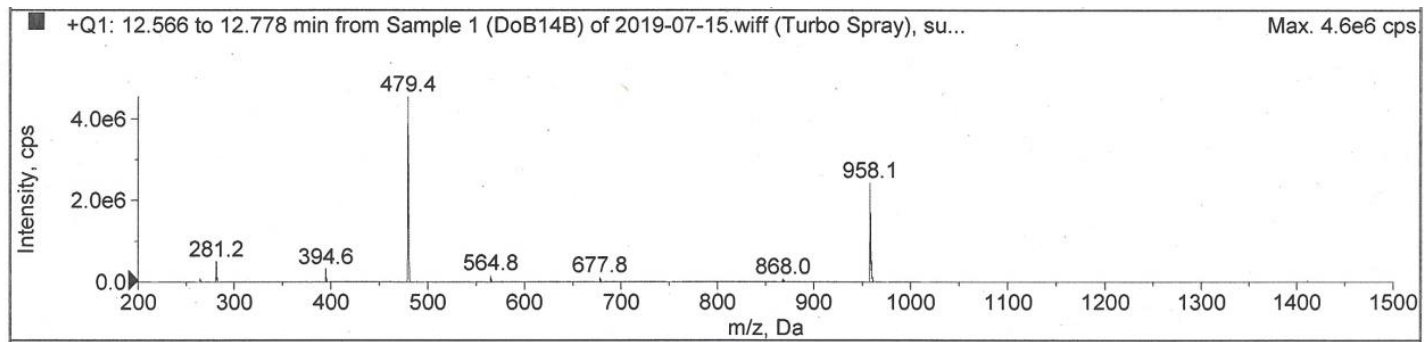


NMR Spectra of Compounds with in vitro Data

${ }^{1} \mathrm{H}$ NMR of compound 21.

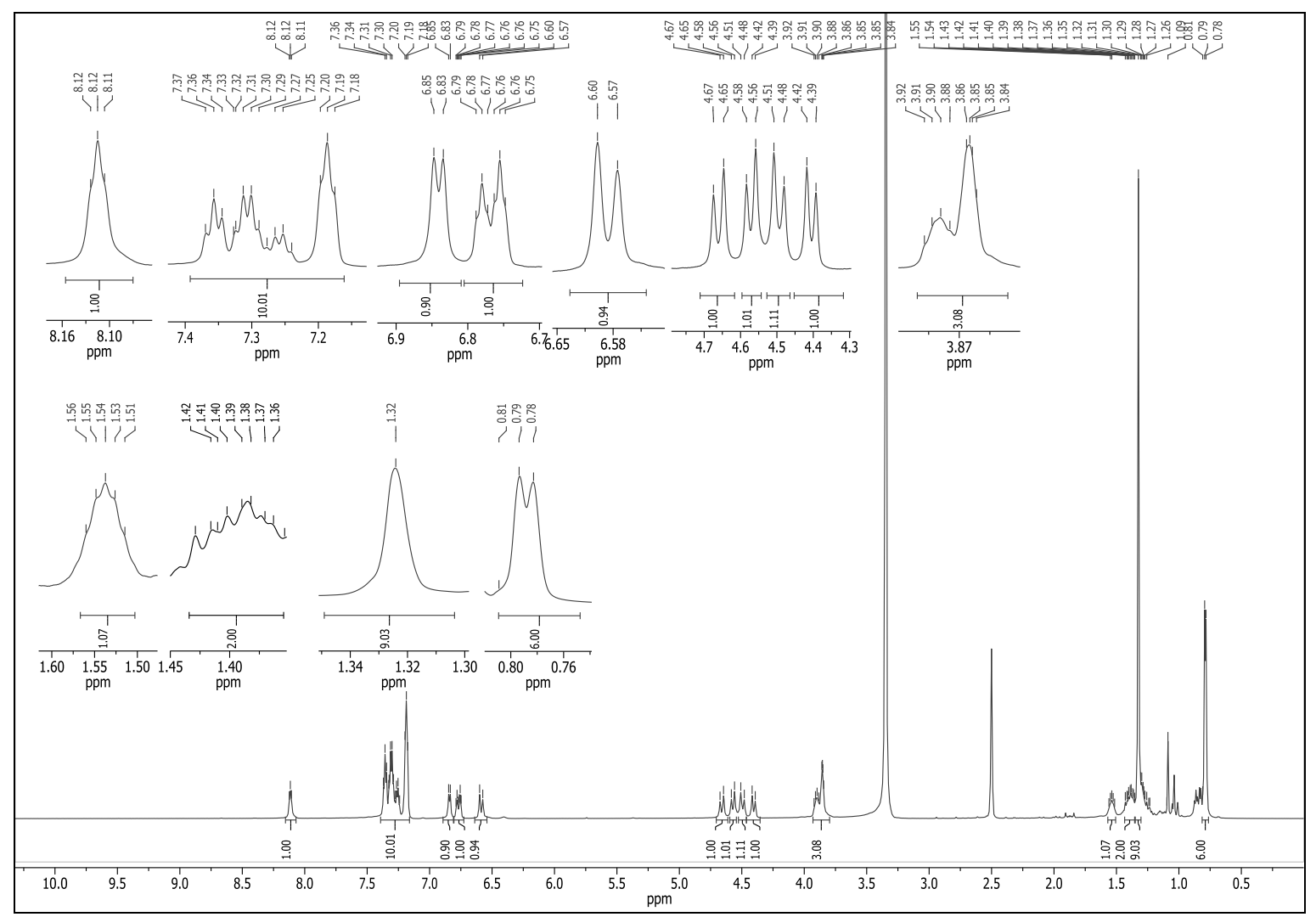

${ }^{13} \mathrm{C}$ NMR of compound 21.

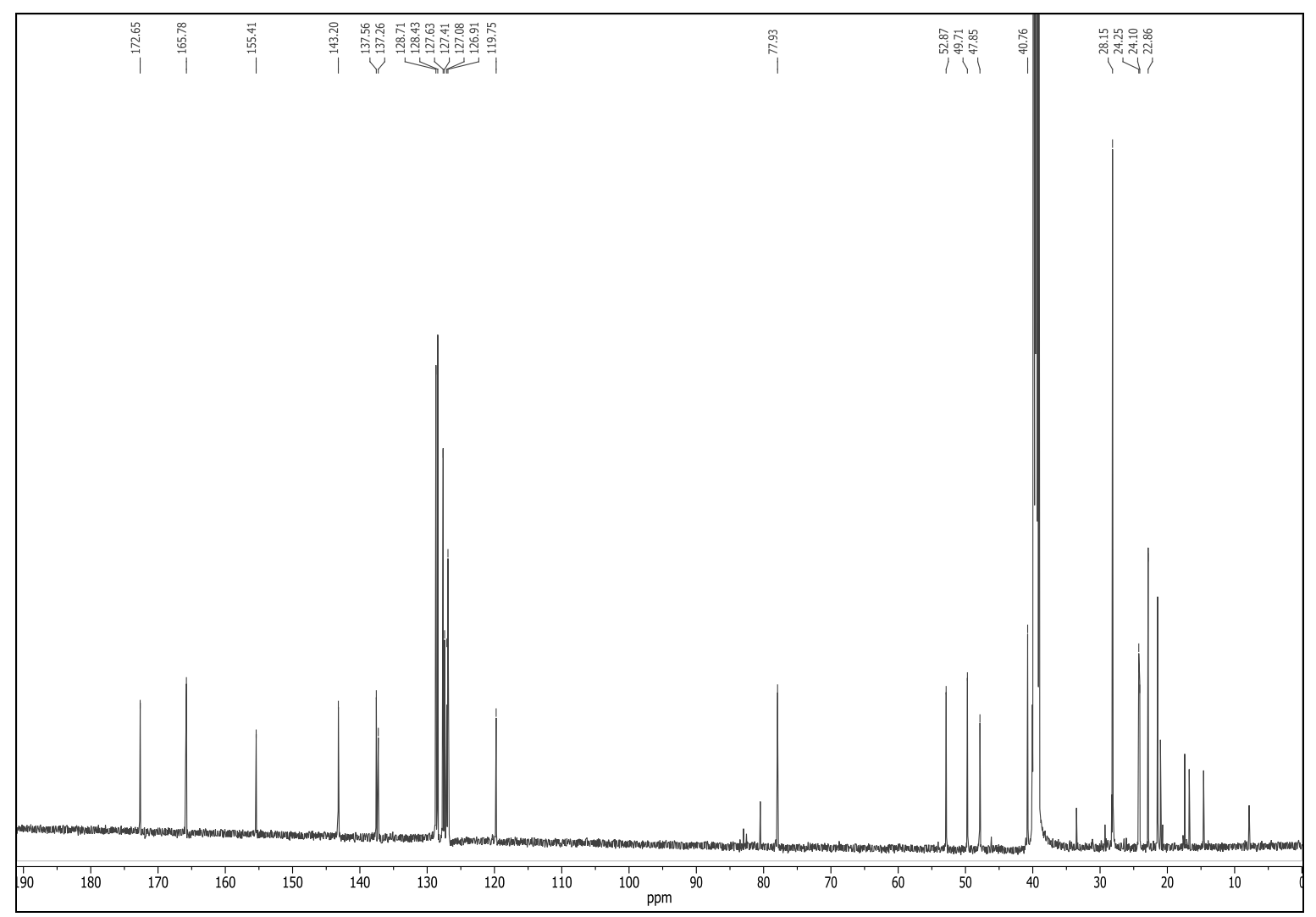


${ }^{1}$ H NMR of compound 22.

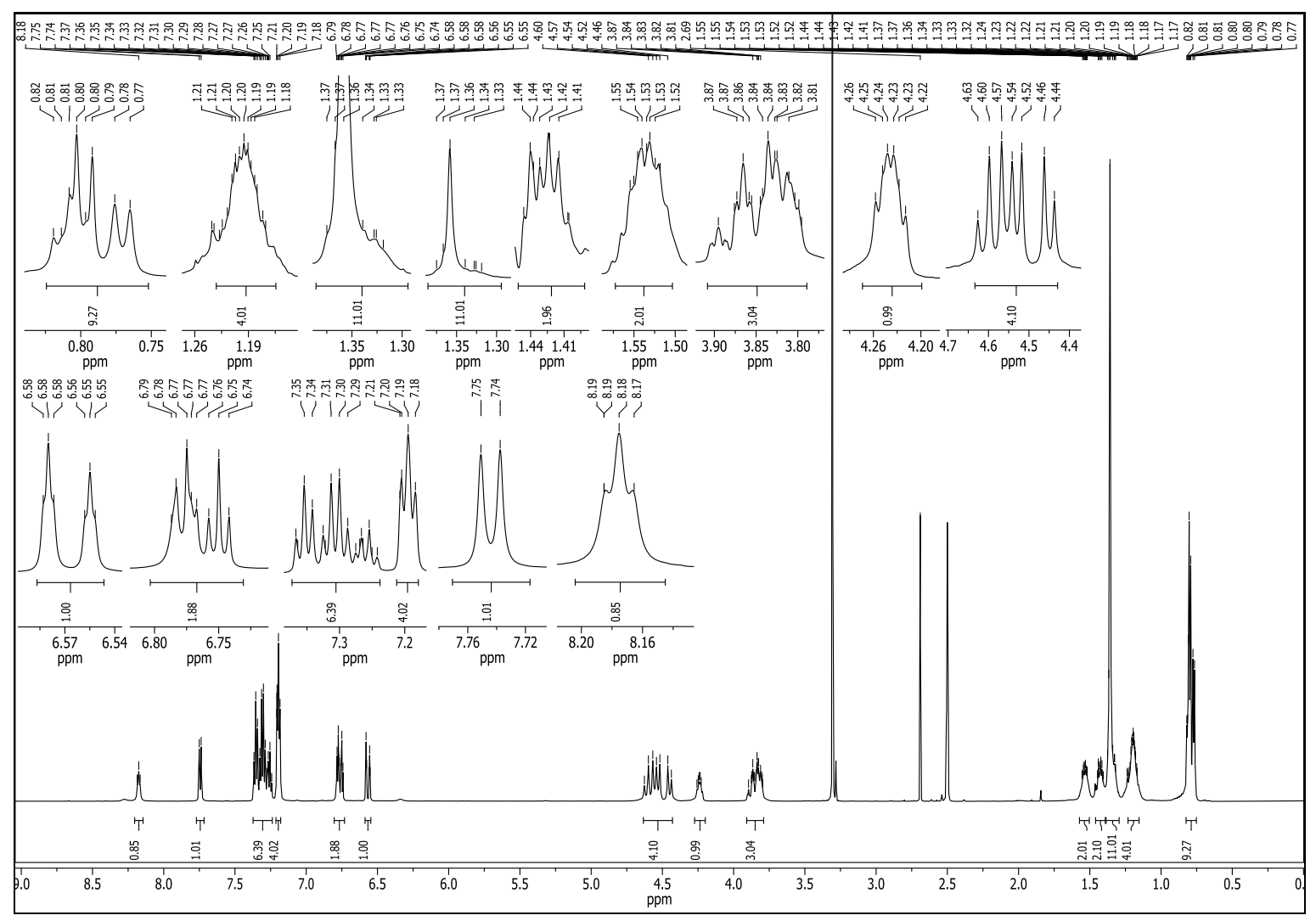

${ }^{13} \mathrm{C}$ NMR of compound 22.

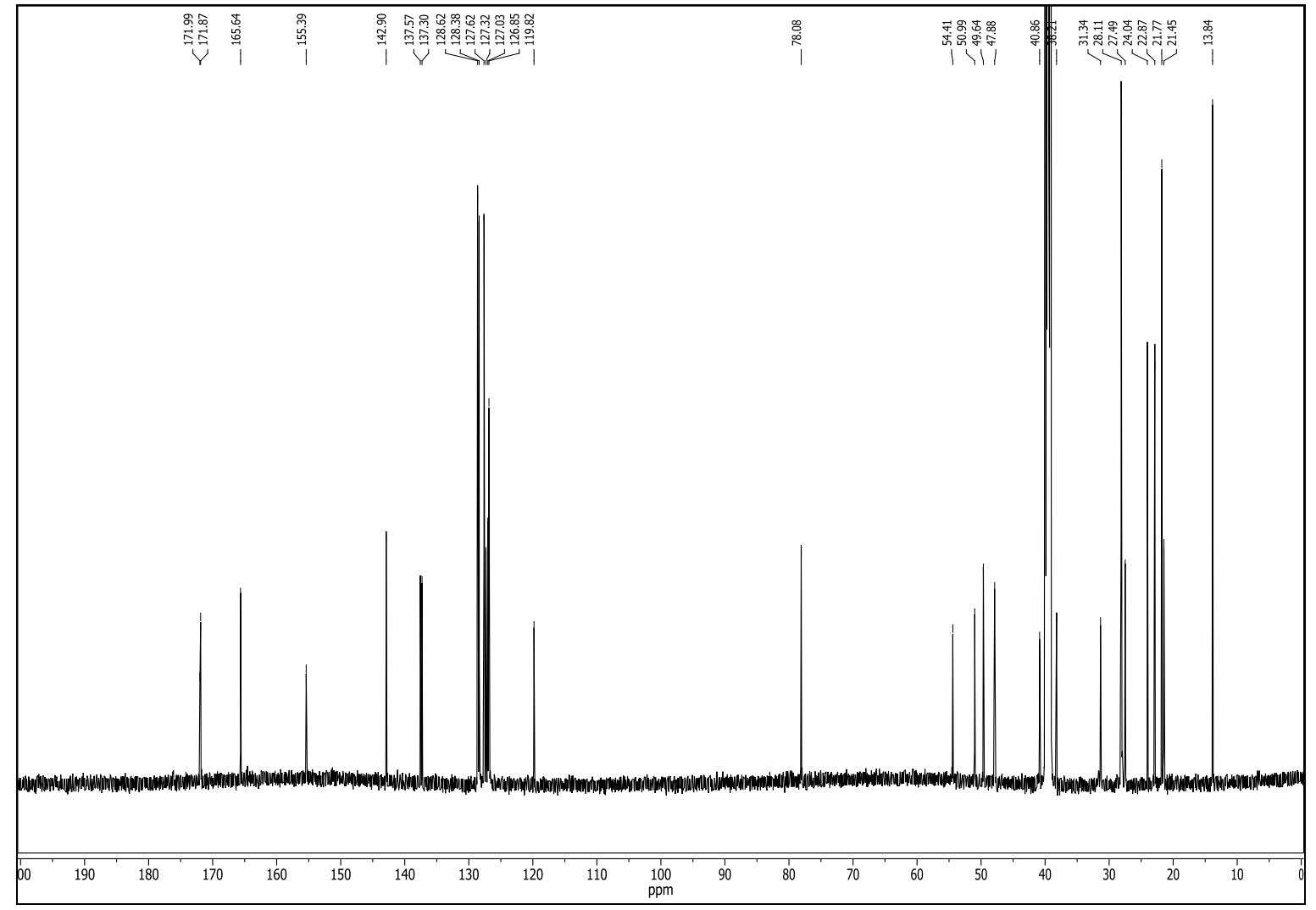


${ }^{1} \mathrm{H}$ NMR of compound 23.

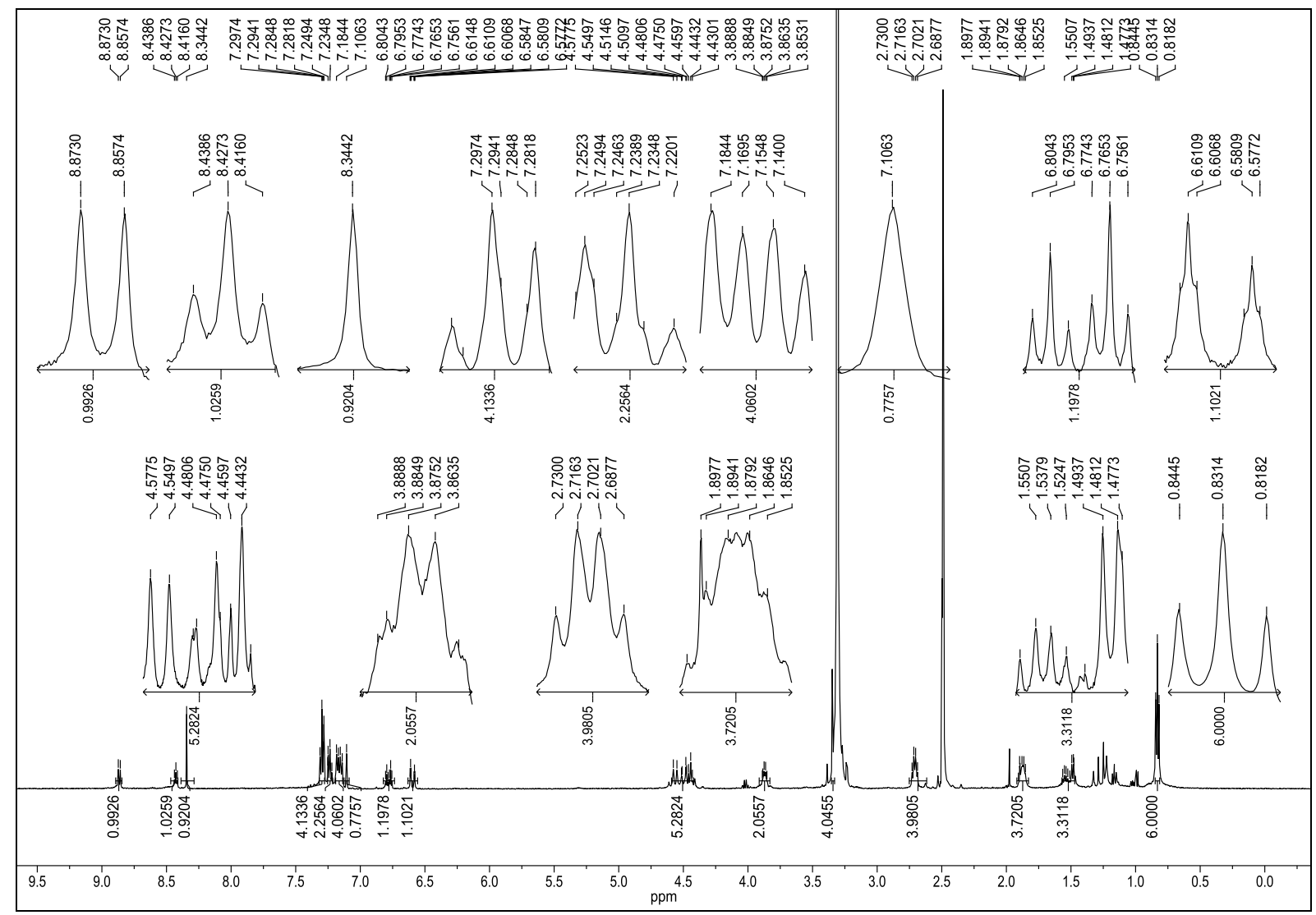

${ }^{13} \mathrm{C}$ NMR of compound 23 .

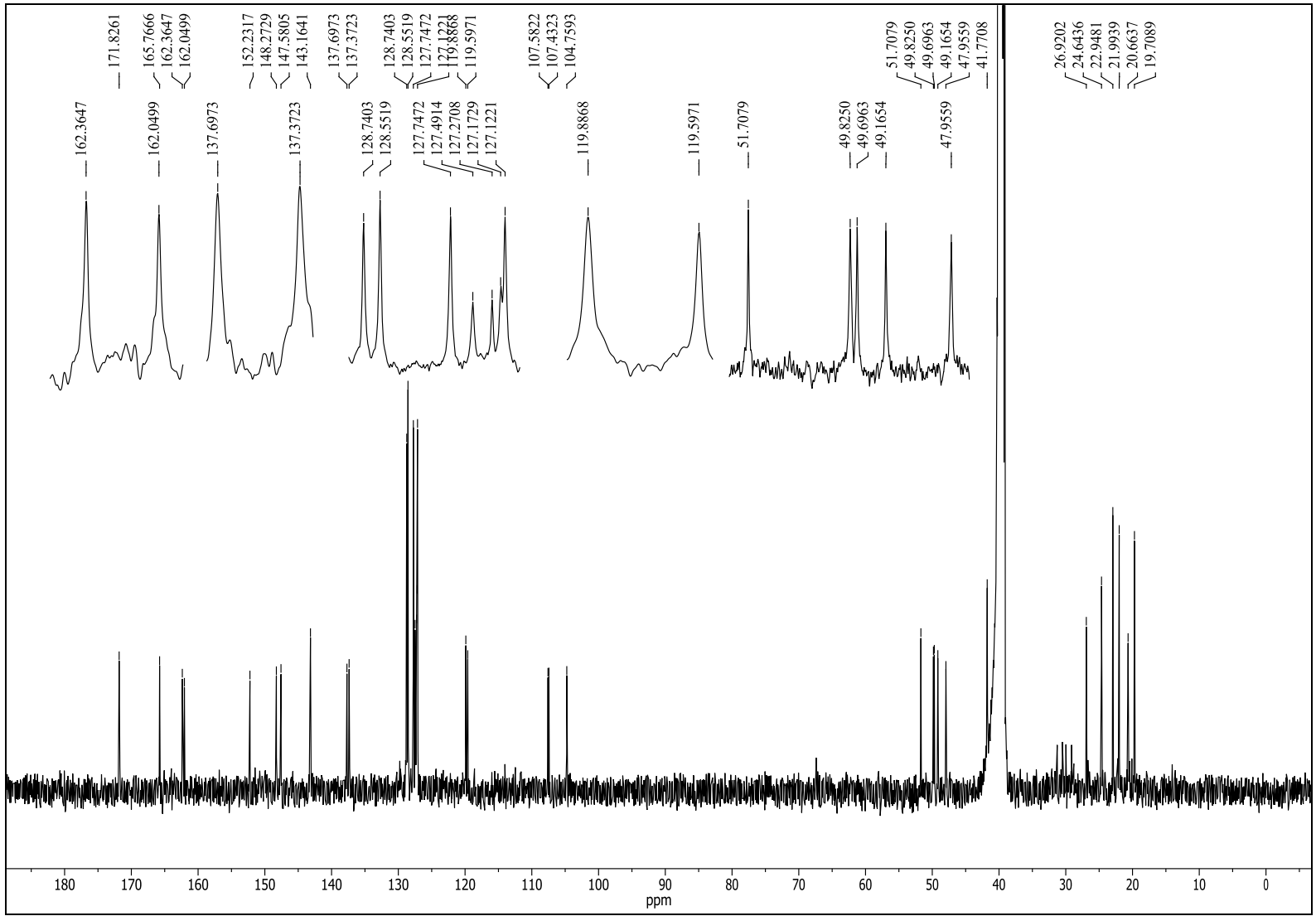


${ }^{1} \mathrm{H}$ NMR of compound 24 .

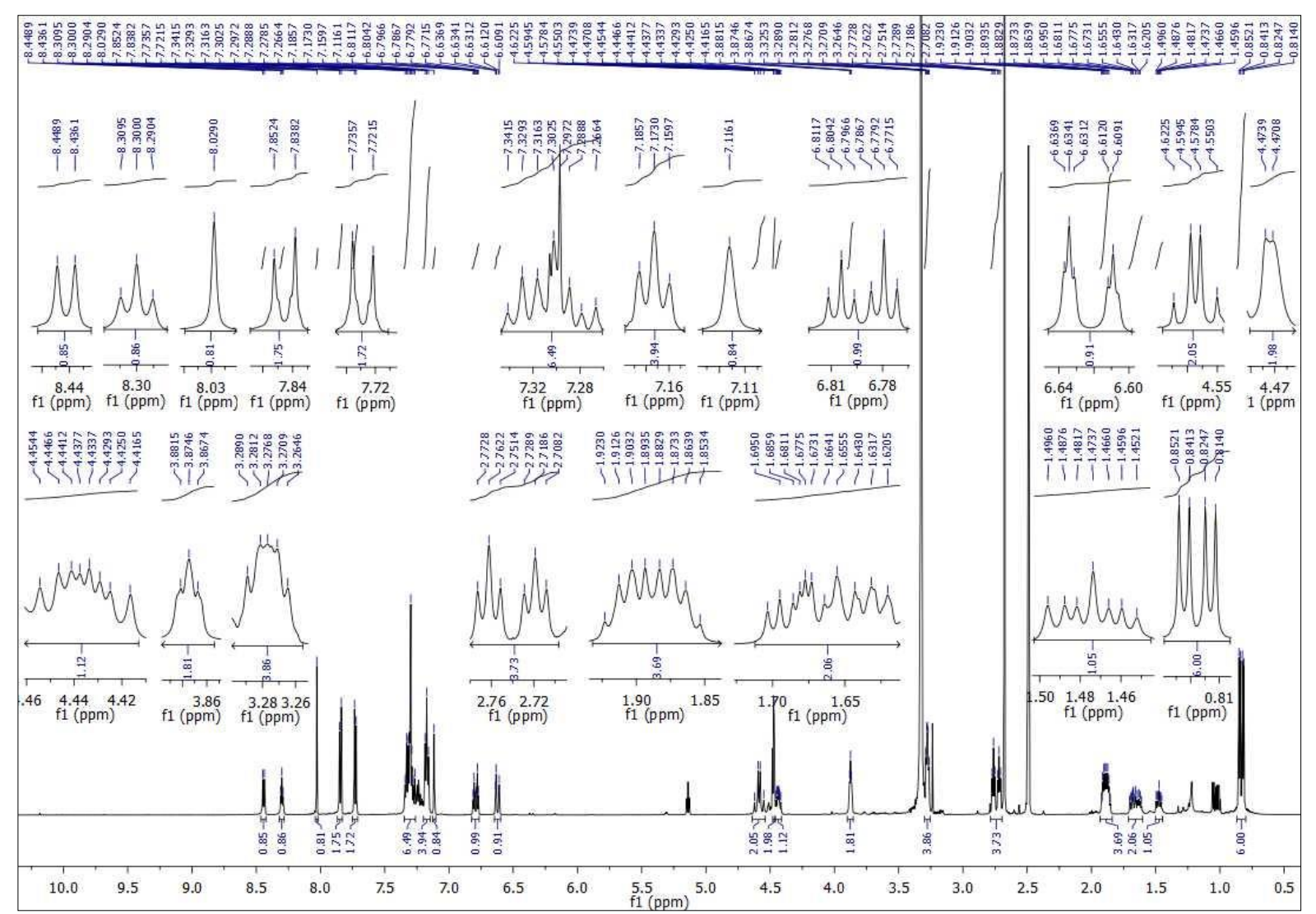

${ }^{13} \mathrm{C}$ NMR of compound 24.

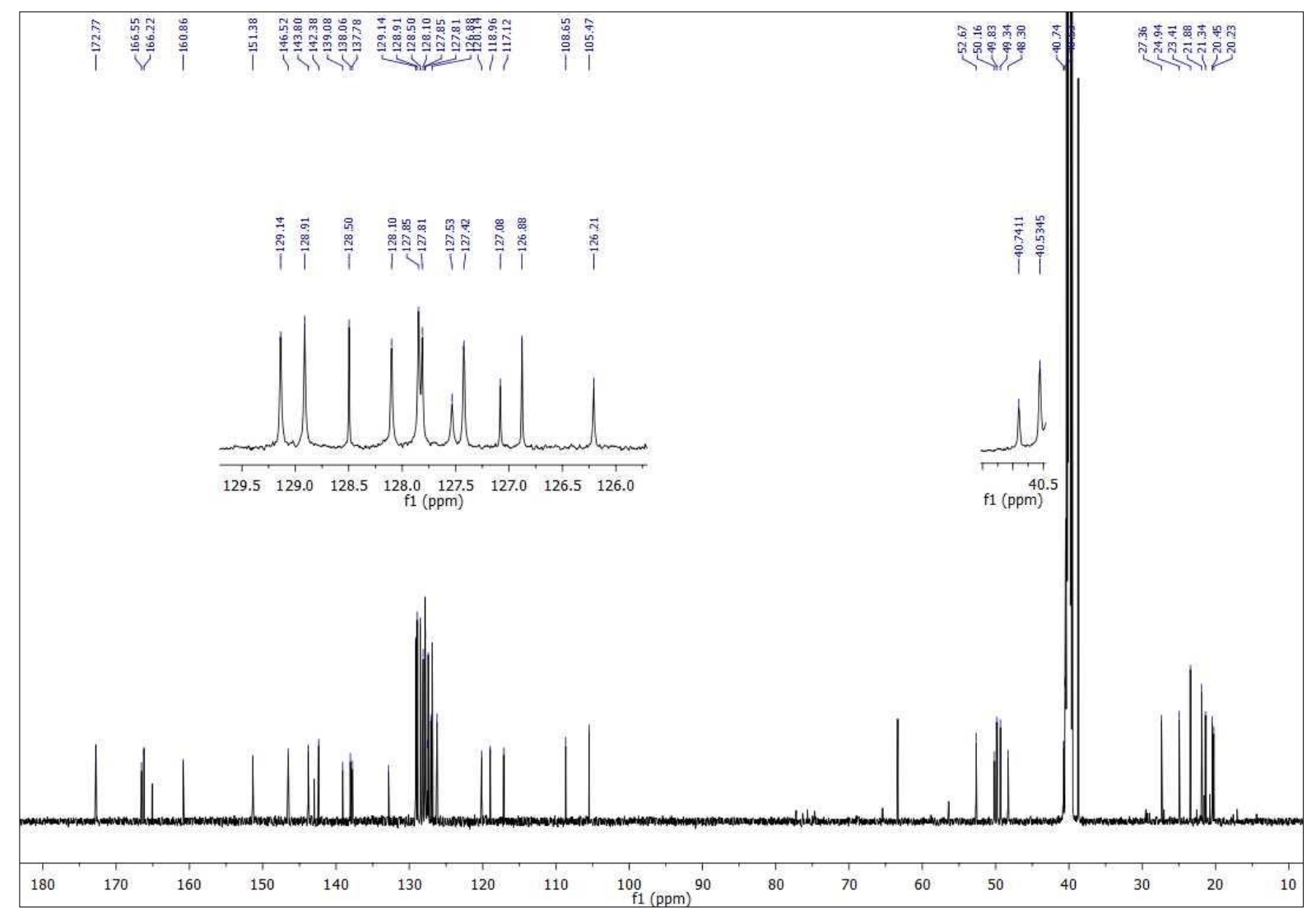


${ }^{1} \mathrm{H}$ NMR of compound 25.

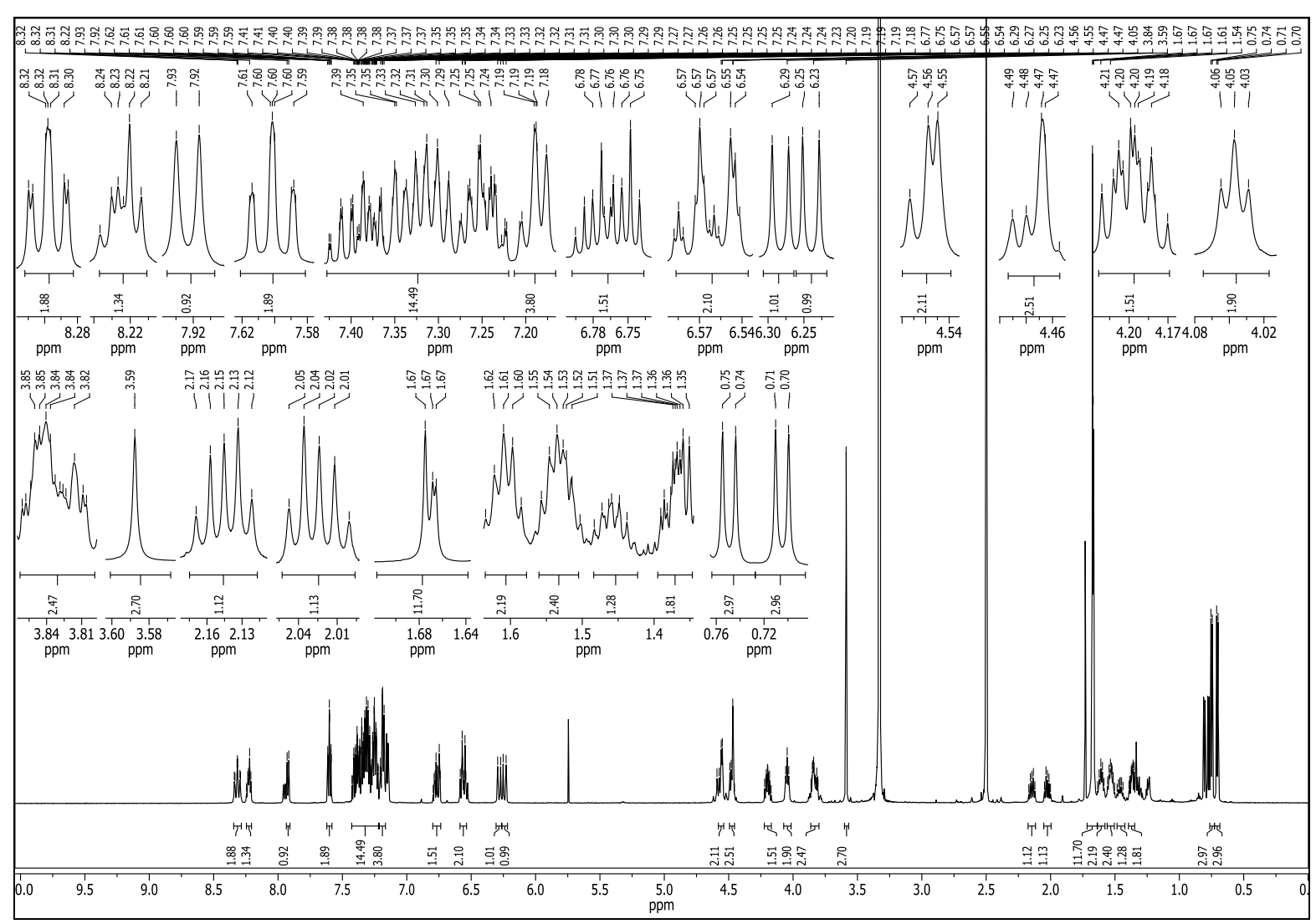

${ }^{13} \mathrm{C}$ NMR of compound 25 .

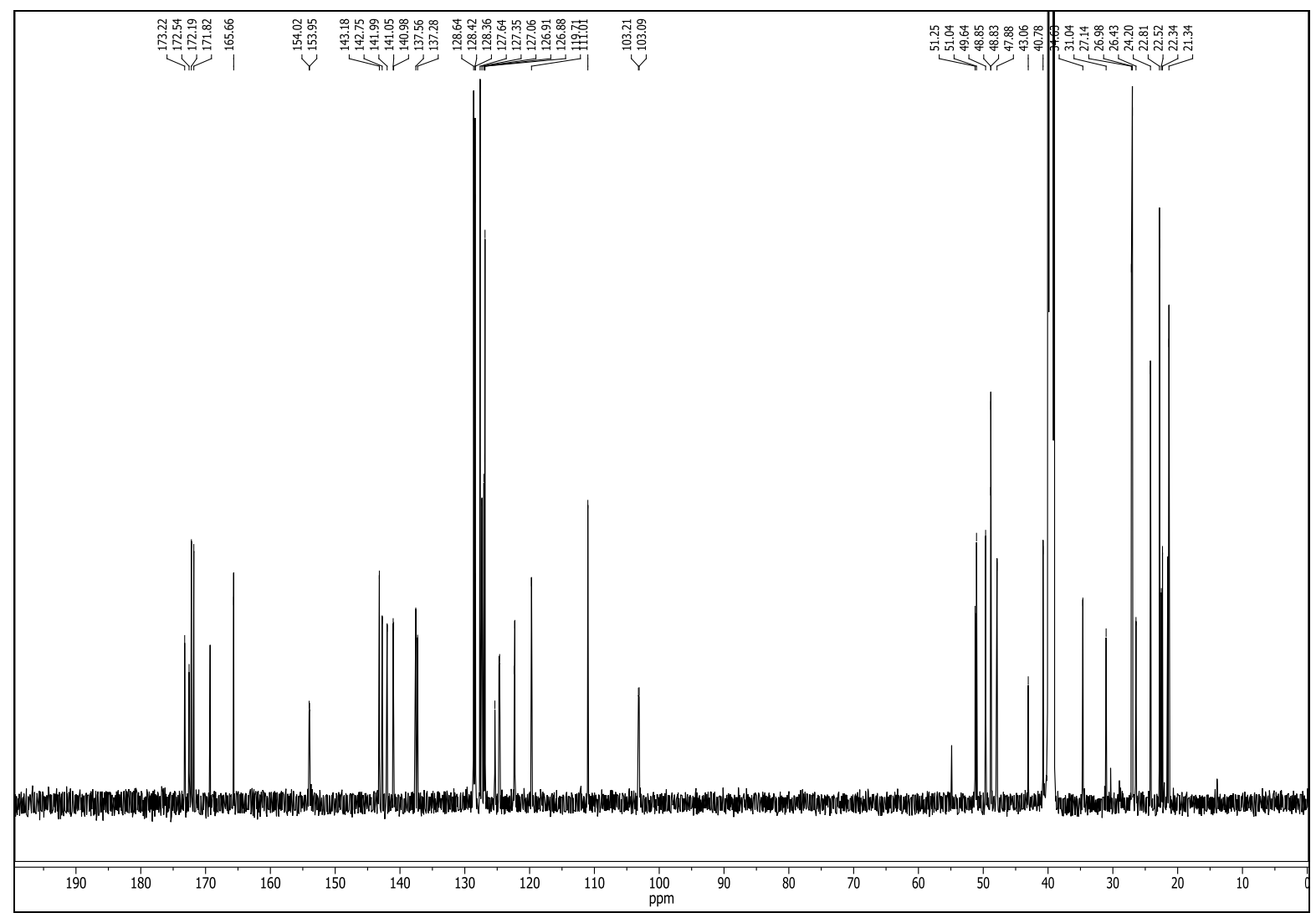


${ }^{1} \mathrm{H}$ NMR of compound $\mathbf{2 6}$.

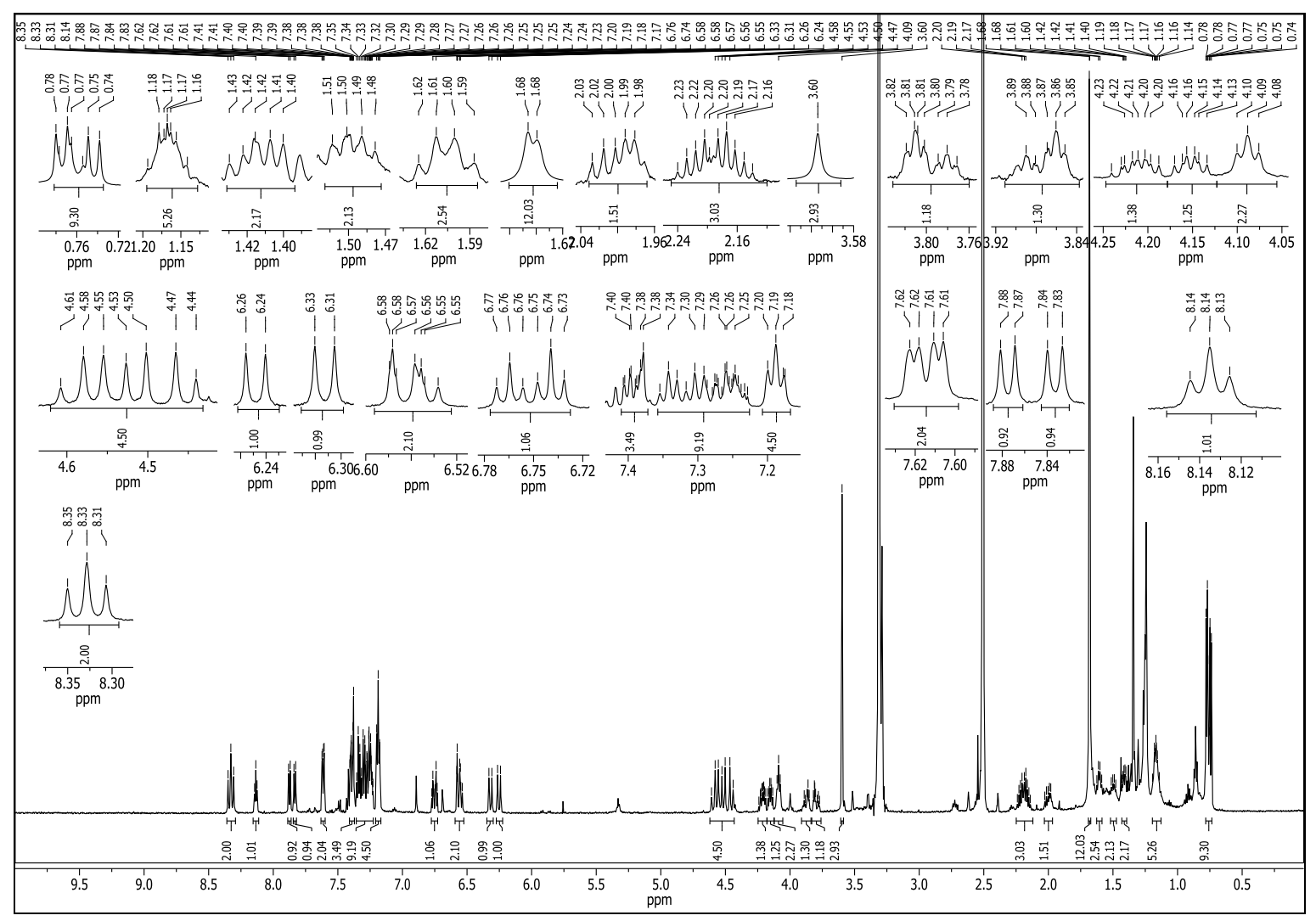

${ }^{13} \mathrm{C}$ NMR of compound 26.

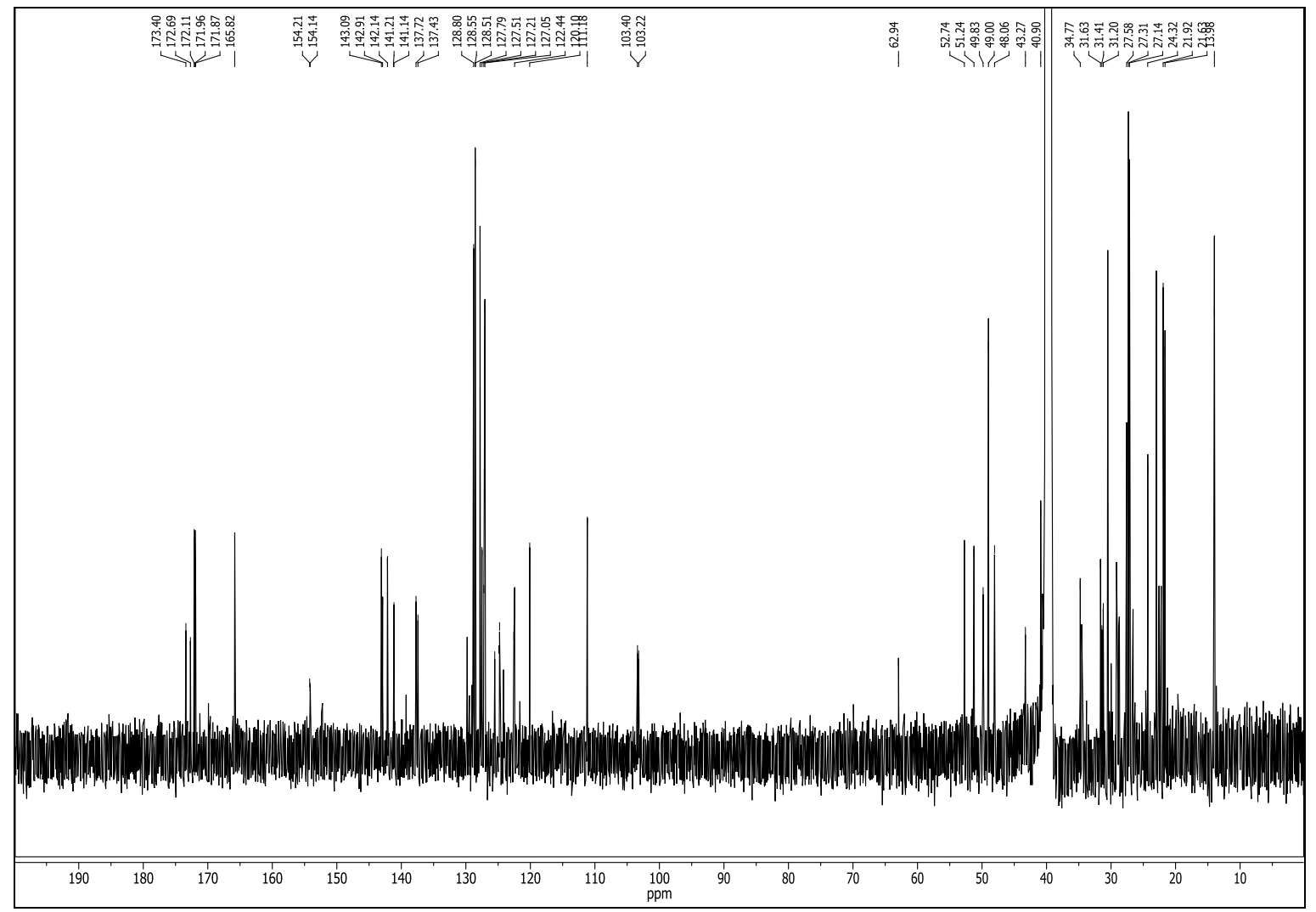




\section{References}

(1) Karplus, P. A.; Diederichs, K. Linking crystallographic model and data quality. Science 2012, 336, 1030-1033.

(2) Brünger, A. T. Free R value: a novel statistical quantity for assessing the accuracy of crystal structures. Nature 1992, 355, 472-475.

(3) Lovell, S. C.; Davis, I. W.; Arendall, W. B., III; de Bakker, P. I.; Word, J. M.; Prisant, M. G.; Richardson, J. S.; Richardson, D. C. Structure validation by C $\alpha$ geometry: $\varphi, \psi$ and C $\beta$ deviation. Proteins: Struct. Funct. Bioinform. 2003, 50, 437-450.

(4) Winn, M. D.; Ballard, C. C.; Cowtan, K. D.; Dodson, E. J.; Emsley, P.; Evans, P. R.; Keegan, R. M.; Krissinel, E. B.; Leslie, A. G. W.; McCoy, A.; McNicholas, S. J.; Murshudov, G. N.; Pannu, N. S.; Potterton, E. A.; Powell, H. R.; Read, R. J.; Vagin, A.; Wilson, K. S. Overview of the CCP4 suite and current developments. Acta Crystallogr. D Biol. Crystallogr. 2011; 67, 235-242. 